\title{
Functional dyspepsia
}

\section{SUMMARY}

Functional dyspepsia is characterised by troublesome early satiety, fullness, or epigastric pain or burning. It can easily be overlooked as the symptoms overlap with gastro-oesophageal reflux disease and irritable bowel syndrome.

Diagnosis is clinical, however it requires exclusion of structural gastrointestinal disease. The presence of red flags, such as weight loss or anaemia, should prompt investigation including gastroscopy.

The pathophysiology of functional dyspepsia is not completely understood. It is thought to be associated with upper gastrointestinal inflammation and motility disturbances, which may be triggered by an infectious or allergenic agent, or a change in the intestinal microbiome. Slow gastric emptying occurs in $20 \%$ of cases.

While functional dyspepsia is distressing and affects quality of life, it has no long-term impacts on mortality.

There are many treatment options available, with varying levels of evidence of efficacy. These include reassurance, dietary modification, acid suppression, prokinetic drugs including fundic relaxors, tricyclic antidepressants, rifaximin and psychological therapy.

\section{Introduction}

Functional dyspepsia is a common problem in Australia and often impacts on quality of life and work productivity. ${ }^{1,2}$ It affects $10 \%$ of the population and is more prevalent in women. ${ }^{3-5}$

Functional dyspepsia refers to troublesome upper gastrointestinal symptoms including inability to finish a meal (early satiety), postprandial fullness, and epigastric pain or burning. ${ }^{6}$ Some patients also complain of nausea, heartburn (although this is not the predominant complaint) and even weight loss (few patients with functional dyspepsia are obese). Peptic ulceration, reflux oesophagitis and gastric cancer may present with identical complaints but the vast majority of patients with these symptoms have functional dyspepsia.

There are two subtypes of functional dyspepsia, although these often overlap in practice (see Box). ${ }^{6}$ The largest group (70\%) have early satiety or postprandial fullness, termed postprandial distress syndrome. The other group experience ulcer-like pain or burning, termed epigastric pain syndrome.

Early satiety is a prevalent symptom in populationbased surveys (5-11\%). 3,4 Unless specifically asked about, it may often be missed or misinterpreted as bloating, discomfort or fullness after eating. These are also very common complaints even if meal size is not affected. ${ }^{3,4}$ Most patients with these symptoms have no serious pathology on routine testing including gastroscopy, and are labelled as having functional or non-ulcer dyspepsia. ${ }^{4,6}$

Correctly diagnosing functional dyspepsia is important to guide appropriate therapy and reduce unnecessary procedures or treatments.

\section{Differential diagnosis}

Distinguishing functional dyspepsia from gastrooesophageal reflux disease (GORD) without oesophagitis has been an area of clinical confusion, as early satiety can occur in both conditions. ${ }^{4,6}$

\section{Box Rome IV diagnostic criteria for functional dyspepsia subtypes}

\section{Postprandial distress syndrome \\ Bothersome postprandial fullness or early satiety severe enough to impact on regular activities or finishing a regular-size meal for 3 or more days per week in the past 3 months, with at least a 6-month history. \\ Epigastric pain syndrome \\ Bothersome epigastric pain or epigastric burning 1 or more days per week in the past 3 months, with at least a 6 -month history.}

Note: both require the absence of evidence of organic systemic, or metabolic disease that is likely to explain the symptoms on routine investigations (including at upper endoscopy).

Source: Reference 6

\section{Nicholas J Talley}

Laureate professor

Pro-vice-chancellor

Thomas Goodsall

Conjoint research fellow'

Registrar ${ }^{2}$

\section{Michael Potter}

Conjoint research fellow

Registrar $^{2}$

'Global Research University of Newcastle

2 Department of

Gastroenterology

John Hunter Hospital

Newcastle

New South Wales

\section{Keywords}

dyspepsia, endoscopy, gastro-oesophageal reflux, $\mathrm{H}_{2}$ receptor antagonists, proton pump inhibitors

Aust Prescr 2017:40:209-13 https://doi.org/10.18773/ austprescr.2017.066 
Recent evidence suggests GORD is often the diagnostic label applied to patients even if they have typical symptoms of functional dyspepsia with little or no heartburn. ${ }^{7}$ In patients with functional dyspepsia and no reflux symptoms, there is a substantially increased risk of GORD developing over the next 10 years. ${ }^{4,8}$ Some patients with GORD who fail to respond to acid suppression with proton pump inhibitors may have functional dyspepsia so they should be asked about their symptoms. ${ }^{4}$ Emerging data suggest GORD and functional dyspepsia are part of the same disease spectrum.

Symptoms of irritable bowel syndrome often overlap with those of functional dyspepsia, with epigastric pain and postprandial fullness often occurring with lower abdominal pain and bloating (diagnostic criteria in irritable bowel syndrome). However, unlike in irritable bowel syndrome, the symptoms of functional dyspepsia alone are not associated with a change in bowel habit. Both can arise after acute infectious gastroenteritis. ${ }^{4}$

Gastroparesis is often confused with functional dyspepsia but is rare. ${ }^{4,6}$ This should be considered in patients with persistent vomiting or weight loss associated with dyspepsia. ${ }^{4,6}$ A nuclear medicine gastric-emptying test can be helpful in this setting.

\section{Pathophysiology}

Functional dyspepsia has been considered an idiopathic disorder but this view is changing. In some cases, functional dyspepsia develops after acute infectious gastroenteritis, suggesting acute intestinal inflammation may play a role. ${ }^{4,6}$

Helicobacter pylori is a recognised cause of functional dyspepsia. ${ }^{9}$ Most patients with $H$. pylori do not develop functional dyspepsia so in many of these cases it is an incidental finding. However in a minority, eradicating the infection cures dyspepsia long term, especially in those with epigastric pain as the main problem. ${ }^{4,9}$

Gastric and duodenal motility disturbances have been observed in functional dyspepsia. Gastric emptying is often normal but may be slow in $25 \%$ of patients or occasionally fast. ${ }^{10}$ However, symptoms have generally not correlated with slow gastric emptying in functional dyspepsia. ${ }^{4}$ Other abnormalities include failure of the gastric fundus to relax normally after eating. This occurs in up to $40 \%$ of patients and is linked to early satiety.., 10 Hypersensitivity to distension of the stomach or duodenum (visceral hypersensitivity) occurs in about one-third of cases. ${ }^{4,11}$

People with postprandial distress have unique duodenal pathology, namely increased duodenal eosinophils that may degranulate..$^{11-15}$ Duodenal eosinophils have been linked to increased mucosal permeability, submucosal neuronal structural and functional changes, and symptoms. ${ }^{12,13}$ They may reflect an infectious or allergenic trigger. In functional dyspepsia, the duodenal microbiome is also abnormal with increased oral streptococci. ${ }^{16}$

Psychological distress is common in patients with functional dyspepsia but may begin after the gut symptoms manifest. 3,8,17 Anxiety is prevalent but depression can occur and should not be missed.

\section{Proposed disease model}

Recently a unifying disease model has been proposed for functional dyspepsia. ${ }^{4}$ Either an infection, microbiome alteration or a food allergen, such as wheat, induces increased duodenal permeability and duodenal eosinophilia with or without increased mast cells. This activates a mucosal immune response. Local duodeno-gastric reflex responses to low-grade inflammation alter gastroduodenal function, including impaired fundic relaxation in a subset of patients. Circulating cytokines such as tumour necrosis factor alpha may lead to systemic and central nervous system symptoms such as anxiety. ${ }^{18}$

These concepts are all supported by experimental evidence and, if correct, the model represents a paradigm shift with profound treatment implications.

\section{Diagnosis}

A typical history of long-standing troublesome early satiety and postprandial fullness is sufficient to make a clinical diagnosis and commence treatment, but often gastroscopy is required. ${ }^{4,6}$ Any of the following red flag symptoms should prompt endoscopy:

- new onset in older age

- unintended weight loss

- vomiting

- bleeding

- iron deficiency anaemia

- family history of upper gastrointestinal cancer

- progressive dysphagia or odynophagia.

It is otherwise reasonable to screen for $H$. pylori infection by breath or stool antigen test and treat positive cases. Non-steroidal anti-inflammatory drugs should be stopped before either investigation or an empiric trial of therapy, usually a proton pump inhibitor for 2-4 weeks, in those who are still symptomatic. ${ }^{4,6}$

If gastroscopy is required, biopsies can be obtained from the duodenum as well as stomach to look for coexistent pathology even if the mucosa looks normal. 


\section{Treatment}

There are many treatment options available for functional dyspepsia, with some being more effective than others (see Table). Many patients will respond to non-pharmacological management and drug therapy should be reserved for refractory cases.

\section{Reassurance and explanation}

Making a firm diagnosis even in the absence of endoscopy is sound medical practice and probably therapeutic. Functional dyspepsia is common and impacts on quality of life, but the good news is there is no associated increased mortality..$^{19}$ Reassurance, explanation and advice to reduce stress should be routine. Depression should be excluded by asking simple screening questions. ${ }^{20}$

\section{Diet}

Traditionally eating smaller regular low-fat meals is the advice offered, as the stomach and duodenum can process these more easily (a high fat intake slows gastric emptying $)^{21}$ and gastric distension is minimised. Wheat may induce typical dyspepsia symptoms. Eliminating it may provide relief in some patients although strong empirical evidence is lacking. ${ }^{22}$ Theoretically a low FODMAP diet, an established therapy for irritable bowel syndrome, may help by reducing upper intestinal distension but there is no empirical evidence in functional dyspepsia. ${ }^{22}$ Other triggers have been

\section{Table Usefulness of therapies for functional dyspepsia}

\begin{tabular}{lll} 
& \multicolumn{2}{c}{ Functional dyspepsia subtypes } \\
\cline { 2 - 3 } & $\begin{array}{l}\text { Epigastric pain } \\
\text { syndrome }\end{array}$ & $\begin{array}{l}\text { Postprandial } \\
\text { distress syndrome }\end{array}$ \\
\hline Reassurance & + & + \\
Diet & + & + \\
Acid & ++ & + \\
suppression & & ++ \\
Prokinetics & + & + \\
Fundic relaxors & - & + \\
Tricyclic & ++ & \\
antidepressants & & + \\
\hline Rifaximin & + & \\
\hline $\begin{array}{l}\text { Psychological } \\
\text { therapy }\end{array}$ & + &
\end{tabular}

- not useful

+ limited evidence of efficacy

++ efficacious identified, including fatty, fried or spicy foods, and carbonated drinks, and avoiding these may be of benefit. ${ }^{23}$

\section{Acid suppression}

Reducing the amount of acid bathing the duodenum may be helpful. ${ }^{4}$ Proton pump inhibitors are superior to placebo in functional dyspepsia. However, they have risks with long-term use. The majority of patients do not respond to this therapy, and it is most useful in those with epigastric pain. ${ }^{24} \mathrm{An}$ alternative is $\mathrm{H}_{2}$ receptor antagonist therapy, which is also superior to placebo. Some patients find this helpful even if proton pump inhibitors have failed. ${ }^{24}$ Antacids and sucralfate are not efficacious. ${ }^{24}$

\section{Prokinetics}

In Australia, domperidone is sometimes prescribed but the evidence for efficacy in functional dyspepsia is very limited. ${ }^{24}$ Cisapride has a better evidence base and is available from compounding chemists. ${ }^{24}$ Both of these drugs prolong the QT interval and must be used with caution. ECG monitoring is recommended. Prokinetics help postprandial distress more than pain. Metoclopramide should be avoided unless nausea is a serious issue as irreversible tardive dyskinesia is a concern. For nausea in such cases a $5 \mathrm{HT}_{3}$ antagonist (ondansetron) is preferred. ${ }^{24}$

\section{Fundic relaxors}

Fundic relaxors can be considered for people unresponsive to prokinetics. Cisapride relaxes the gastric fundus, but alternative options include the anti-anxiety drug buspirone ${ }^{25}$ or the over-the-counter product lberogast. ${ }^{26}$

\section{Antidepressants}

Low-dose tricyclic antidepressants are superior to placebo for functional dyspepsia, but they are probably most helpful for those with epigastric pain. ${ }^{27,28}$ Consider amitriptyline $10-25 \mathrm{mg}$ at night increasing to $50 \mathrm{mg}$ if tolerated after 2-4 weeks. Some people may need doses up to $100 \mathrm{mg}$. These doses may be associated with adverse effects, especially in older patients.

Selective serotonin reuptake inhibitors and selective noradrenaline reuptake inhibitors are reported to be no better than placebo. ${ }^{27}$ Mirtazepine may have some efficacy particularly if nausea is associated. ${ }^{29}$

\section{Non-absorbable antibiotic rifaximin}

The microbiome is disturbed in functional dyspepsia. One randomised controlled trial from Hong Kong has reported rifaximin was superior to placebo, although this is currently an expensive off-label therapy and data 
on relapse and retreatment are not available. ${ }^{30}$ While rifaximin's predominant effect in functional dyspepsia is believed to be antibiotic, its anti-inflammatory properties may contribute to symptom relief. ${ }^{30}$

\section{Psychological therapy}

Evidence for psychological therapy in functional dyspepsia is limited. However, for patients with a strong psychological component, offering cognitive behavioural therapy is reasonable. ${ }^{4,6}$

\section{The future}

Low-grade duodenal inflammation may be amenable to anti-inflammatory therapy and possible cure. An eosinophil-stabilising drug montelukast appeared to have efficacy in children with functional dyspepsia. ${ }^{31}$

\section{Conclusion}

Functional dyspepsia is common, and the diagnosis can be made clinically in the absence of red flags. Concerning features on history or physical examination should prompt referral to a gastroenterologist for consideration of gastroscopy. Although symptoms can be significantly troublesome or disabling, there is no long-term effect on mortality. Multiple pharmacological and non-pharmacological therapies are available for patients with functional dyspepsia, giving clinicians several options for managing patients with this condition. $<$

Nicholas Talley has received grants and research support from: Abbott Pharmaceuticals (IBS), Commonwealth Diagnostics (International), Janssen (constipation), Prometheus (IBS), Pfizer (at Mayo Clinic), Rome Foundation and Salix (at Mayo Clinic). He has patents on: biomarkers of irritable bowel syndrome, licensing questionnaires (Mayo Clinic), Nestec European Patent Application No. 12735358.9 and New Singapore 'Provisional' Patent NTU Ref: TD/129/17 'Microbiota Modulation of BDNF Tissue Repair Pathway'. He has been involved with the following consultancies: Adelphi values (functional dyspepsia working group to develop a symptom-based PRO instrument), Allergens PLC (GI development programs), GI therapies (non-invasive device company, consultant and options), Napo Pharmaceutical, Outpost Medicine, Samsung Bioepis and Yuhan (IBS).

\section{REFERENCES}

1. Aro P, Talley NJ, Agréus L, Johansson SE Bolling-Sternevald E, Storskrubb T, et al. Functiona dyspepsia impairs quality of life in the adult population. Aliment Pharmacol Ther 2011;33:1215-24. https://doi.org/ 10.1111/j.1365-2036.2011.04640.x

2. Lacy BE, Weiser KT, Kennedy AT, Crowell MD, Talley NJ. Functional dyspepsia: the economic impact to patients. Aliment Pharmacol Ther 2013;38:170-7. https://doi.org/10.1111/ apt.12355

3. Koloski NA, Jones M, Talley NJ. Evidence that independent gut-to-brain and brain-to-gut pathways operate in the irritable bowel syndrome and functional dyspepsia: a 1-year population-based prospective study. Aliment Pharmacol Ther 2016:44:592-600. https://doi.org/10.1111/apt.13738

4. Talley NJ, Ford AC. Functional Dyspepsia. N Engl J Med 2015;373:1853-63. https://doi.org/10.1056/NEJMra1501505

5. Koloski NA, Jones M, Weltman M, Kalantar J, Bone C, Gowryshankar A, et al. Identification of early environmental risk factors for irritable bowel syndrome and dyspepsia. Neurogastroenterol Motil 2015;27:1317-25. https://doi.org/ 10.1111/nmo.12626

6. Stanghellini V, Chan FK, Hasler WL, Malagelada JR, Suzuki H, Tack J, et al. Gastroduodenal Disorders. Gastroenterology 2016;150:1380-92. https://doi.org/10.1053/j.gastro.2016.02.011

7. Pleyer $\mathrm{C}$, Bittner $\mathrm{H}$, Locke GR III, Choung RS, Zinsmeister AR, Schleck CD, et al. Overdiagnosis of gastro-esophageal reflux disease and underdiagnosis of functional dyspepsia in a USA community. Neurogastroenterol Motil 2014;26:1163-71. https://doi.org/10.1111/nmo.12377

8. Aro P, Talley NJ, Johansson SE, Agréus L, Ronkainen J. Anxiety is linked to new-onset dyspepsia in the Swedish population: a 10-year follow-up study. Gastroenterology 2015;148:928-37. https://doi.org/10.1053/j.gastro.2015.01.039

9. Sugano K, Tack J, Kuipers EJ, Graham DY, El-Omar EM, Miura S, et al.; faculty members of Kyoto Global Consensus Conference. Kyoto global consensus report on Helicobacter pylori gastritis. Gut 2015;64:1353-67. https://doi.org/10.1136/ gutjnl-2015-309252

10. Vanheel H, Carbone F, Valvekens L, Simren M, Tornblom H, Vanuytsel $\mathrm{T}$, et al. Pathophysiological abnormalities in functional dyspepsia subgroups according to the Rome III criteria. Am J Gastroenterol 2017;112:132-40. https://doi.org/10.1038/ajg.2016.499
11. Talley NJ, Walker MM, Aro P, Ronkainen J, Storskrubb T, Hindley LA, et al. Non-ulcer dyspepsia and duodenal eosinophilia: an adult endoscopic population-based casecontrol study. Clin Gastroenterol Hepatol 2007:5:1175-83. https://doi.org/10.1016/j.cgh.2007.05.015

12. Cirillo C, Bessissow T, Desmet AS, Vanheel H, Tack J, Vanden Berghe P. Evidence for neuronal and structural changes in submucous ganglia of patients with functional dyspepsia. Am J Gastroenterol 2015;110:1205-15. https://doi.org/10.1038/ajg.2015.158

13. Vanheel H, Vicario M, Vanuytsel T, Van Oudenhove L, Martinez C, Keita AV, et al. Impaired duodenal mucosal integrity and low-grade inflammation in functional dyspepsia. Gut 2014;63:262-71. https://doi.org/10.1136/ gutjnl-2012-303857

14. Walker MM, Aggarwal KR, Shim LS, Bassan M, Kalantar JS, Weltman MD, et al. Duodenal eosinophilia and early satiety in functional dyspepsia: confirmation of a positive association in an Australian cohort. J Gastroenterol Hepatol 2014;29:474-9. https://doi.org/10.1111/jgh.12419

15. Walker MM, Talley NJ. The role of duodenal inflammation in functional dyspepsia. J Clin Gastroenterol 2017;51:12-8. https://doi.org/10.1097/MCG.0000000000000740

16. Zhong L, Shanahan ER, Raj A, Koloski NA, Fletcher L, Morrison M, et al. Dyspepsia and the microbiome: time to focus on the small intestine. Gut 2016 Aug 03 published online first. https://doi.org/10.1136/gutjnl-2016-312574

17. Aro P, Talley NJ, Ronkainen J, Storskrubb T, Vieth M, Johansson SE, et al. Anxiety is associated with uninvestigated and functional dyspepsia (Rome III criteria) in a Swedish population-based study. Gastroenterology 2009;137:94-100. https://doi.org/10.1053/j.gastro.2009.03.039

18. Liebregts T, Adam B, Bredack C, Röth A, Heinzel S, Lester S, et al. Immune activation in patients with irritable bowe syndrome. Gastroenterology 2007;132:913-20. https://doi.org/10.1053/j.gastro.2007.01.046

19. Chang JY, Locke GR 3rd, McNally MA, Halder SL, Schleck CD, Zinsmeister AR, et al. Impact of functional gastrointestinal disorders on survival in the community. Am J Gastroenterol 2010;105:822-32. https://doi.org/10.1038/ajg.2010.40

20. Arroll B, Goodyear-Smith F, Kerse N, Fishman T, Gunn J. Effect of the addition of a "help" question to two screening questions on specificity for diagnosis of depression in general practice: diagnostic validity study. BMJ 2005;331:884. https://doi.org/10.1136/bmj.38607.464537.7C 
21. Pilichiewicz AN, Feltrin KL, Horowitz M, Holtmann G, Wishart JM, Jones $\mathrm{KL}$, et al. Functional dyspepsia is associated with a greater symptomatic response to fat but not carbohydrate, increased fasting and postprandial CCK, and diminished PYY. Am J Gastroenterol 2008:103:2613-23. https://doi.org/10.1111/j.1572-0241.2008.02041.x

22. Volta U, Caio G, Karunaratne TB, Alaedini A, De Giorgio R. Non-coeliac gluten/wheat sensitivity: advances in knowledge and relevant questions. Expert Rev Gastroenterol Hepatol 2017;11:9-18. https://doi.org/10.1080/17474124.2017.1260003

23. Göktaș Z, Köklü S, Dikmen D, Öztürk Ö, Yılmaz B, Asıl M, et al. Nutritional habits in functional dyspepsia and its subgroups: a comparative study. Scand J Gastroentero 2016;51:903-7. https://doi.org/10.3109/00365521.2016.1164238

24. Zala AV, Walker MM, Talley NJ. Emerging drugs for functional dyspepsia. Expert Opin Emerg Drugs 2015;20:221-33. https://doi.org/10.1517/14728214.2015.1009827

25. Tack J, Janssen P, Masaoka T, Farré R, Van Oudenhove L. Efficacy of buspirone, a fundus-relaxing drug, in patients with functional dyspepsia. Clin Gastroenterol Hepatol 2012;10:1239-45. https://doi.org/10.1016/j.cgh.2012.06.036

26. Holtmann G, Talley NJ. Herbal medicines for the treatment of functional and inflammatory bowel disorders. Clin Gastroenterol Hepatol 2015;13:422-32. https://doi.org/ 10.1016/j.cgh.2014.03.014
27. Ford AC, Luthra P, Tack J, Boeckxstaens GE, Moayyedi P, Talley NJ. Efficacy of psychotropic drugs in functional dyspepsia: systematic review and meta-analysis. Gut 2017;66:411-20. https://doi.org/10.1136/gutjnl-2015-310721

28. Talley NJ, Locke GR, Saito YA, Almazar AE, Bouras EP, Howden CW, et al. Effect of amitriptyline and escitalopram on functional dyspepsia: a multicenter, randomized controlled study. Gastroenterology 2015;149:340-9.e2. https://doi.org/10.1053/j.gastro.2015.04.020

29. Tack J, Ly HG, Carbone F, Vanheel H, Vanuytsel T, Holvoet L, et al. Efficacy of mirtazapine in patients with functional dyspepsia and weight loss. Clin Gastroenterol Hepatol 2016;14:385-92.e4. https://doi.org/10.1016/j.cgh.2015.09.043

30. Tan VP, Liu KS, Lam FY, Hung IF, Yuen MF, Leung WK. Randomised clinical trial: rifaximin versus placebo for the treatment of functional dyspepsia. Aliment Pharmacol Ther 2017;45:767-76. https://doi.org/10.1111/apt.13945

31. Friesen CA, Neilan NA, Schurman JV, Taylor DL, Kearns GL, Abdel-Rahman SM. Montelukast in the treatment of duodenal eosinophilia in children with dyspepsia: effect on eosinophil density and activation in relation to pharmacokinetics. BMC Gastroenterol 2009;9:32. https://doi.org/10.1186/1471-230X-9-32

\section{FURTHER READING}

Keung C, Hebbard G. The management of gastro-oesophageal reflux disease. Aust Prescr 2016;39:6-10. https://doi.org/10.18773/ austprescr.2016.003 